\title{
28 Research Suare \\ Escort of the elderly patient into the operating room: a feasibility study
}

\section{Lior Shem Tov}

Tel Aviv Sourasky Medical Center

llai Ronel ( $\square$ ilai.ronel@gmail.com )

Tel Aviv Sourasky Medical Center

Idit Matot

Tel Aviv Sourasky Medical Center

Research article

Keywords: Elderly, surgery, satisfaction, anxiety, family

Posted Date: October 24th, 2019

DOI: https://doi.org/10.21203/rs.2.16437/v1

License: (1) This work is licensed under a Creative Commons Attribution 4.0 International License.

Read Full License 


\section{Abstract}

Background While special care is given to peri-operative risk assessment and management of the elderly undergoing surgery, psychological aspects have been largely neglected. Escort presence in the operating room (OR) is common practice in the surgical pediatric and obstetric populations, and may be beneficial in the elderly.Aims This study explored the feasibility of family member escort of the elderly into the OR and their presence until induction of anesthesia.

Methods Prospective cohort of elderly patients ( $>70$ years) undergoing surgery, who were offered an escort into the OR. The primary endpoint was the proportion of relatives who completed the intervention without feeling dizzy or fainting. Secondary endpoints related to patient, escort and medical staff perception of the process.

Results Forty-four sets of patients and escorts completed the process. The primary objective assessing feasibility was concluded successfully. Secondary objectives assessed (1) satisfaction, where $93 \%$ of escorts and $75 \%$ patients would support a repeat of this process; (2) anxiolysis, where $61.4 \%$ of patients reported a reduced level of anxiety; (3) although $68.2 \%$ of anesthesiologists agreed this process improved that patients' well-being, most anesthesiologists and nurses believed this should not become routine practice. Interestingly, most staff support parents escorting a pediatric patient into OR.

Conclusion This is the first study exploring the feasibility of escorting the elderly into the OR. It shows a unique insight into patient- and family-centered care of the surgical elderly patient. Escort presence may help alleviate anxiety and increase satisfaction. The medical staff objections must be looked at further.

\section{Background}

The increase in life expectancy brought with it a rise in the number of operations performed in the elderly population, to which the health systems must adapt [1, 2]. In recent years the perioperative management of the elderly has gone through significant changes. While special care is given to operative risk assessment and perioperative management (frailty scoring, cognitive assessment, delirium prevention etc.), the psychological aspects have been largely neglected [3-6]. As opposed to the pediatric population, where there is heightened awareness to the emotional needs of both child and parents [7], it is fair to say that this recognition has yet been addressed when confronted with the elderly patient. For example, as part of standard operating room (OR) safety protocols, the patient's visual and hearing aids are removed. This may negatively impact on the elderly ability to orientate in time and space, thus increasing their feelings of anxiety and confusion surrounding their operation.

In recent years a new patient and family centered care approach has been adopted, with the opinion that there is benefit in the involvement of the patient and his family in the planning and giving of medical treatments [8]. This approach is valid for all ages or medical scenarios. For example, it is a common practice that parents accompany their child into the OR. It is also common in the obstetric population where partners stay with the parturient while she is having her epidural or cesarean delivery. Presence of 
families during cardiopulmonary resuscitation had also been encouraged in some places $[7,9,10]$. This practice may assist in reducing anxiety and improve satisfaction. Reducing anxiety is important as it was found to be an independent risk factor for postoperative morbidity in the elderly [11]. Additionally, in recent years improved patient satisfaction has become an essential part of quality assessment of the health care system [12].

A caring environment that includes physical touch and reassurance might improve the overall surgical experience of the elderly. In the literature review made, we have not found any study that aimed to explore the option of family member escort of the elderly patient into the OR and their presence until the induction of anesthesia. We thus, wished to evaluate the feasibility of such program.

\section{Methods}

\section{Participants}

In the preoperative assessment clinic of the Tel Aviv Medical Centre, 50 patients and their escorts (family member or close friend) were approached during 2017, and 44 were recruited to participate in this study. The inclusion criteria consisted of patients over the age of 70 that came in the preoperative anesthesia outpatient clinic, intended to undergo surgery under anesthesia. The exclusion criteria included any patient requiring invasive monitoring prior to induction of anesthesia, patient refusal or inability to sign a consent form. Ethical approval for this study (Ethical Committee number 0212-14-TLV) was provided by the Ethical Committee of the Tel Aviv Sourasky Medical Center, Tel Aviv, Israel, and conforms to the Helsinki declaration.

\section{Design and procedure}

The patients and escorts at the preoperative anesthesia outpatient clinic were given a thorough explanation of the procedure by the attending anesthesiologist. It was also emphasized that the escort presence is defined as an offer of psychological support from a loved one, not the intraoperative presence of a passive or curious observer. Both patient and chosen escort gave verbal and written consent. Preoperatively, patients and escorts completed a questionnaire packet that included two sections: (1) detailed demographics and (2) queries pertaining to the main cause for their wish to escort or be escorted to the OR. This section included the following: (i) The patient's perspectivespresence of my relative: (a) will calm me down, (b) will help me calm down my relative, (c) will help me with communication, (d) other reason; (ii) The escort perspective-I wish to escort my relative to the OR: (a) to calm down my relative, (b) to help with communication, (c) I feel I am expected to do so, (d) other reason. The anesthesiologist assigned to the patient took thorough medical history including diagnosis of general anxiety or depressive disorder and the routine use of antidepressants, anxiolytics, or psychiatric services.

\section{Intervention protocol}


Preoperative anxiety levels were assessed using the Amsterdam Preoperative Anxiety and Information Scale (APAIS) [13]. The APAIS is a self-report questionnaire comprising six questions that have been developed and validated to evaluate the preoperative anxiety of patients. The APAIS correlates with the State-Anxiety-Scale (STAI) and has been applied in different surgical populations [14-18]. Various version in multiple languages proved its validity with performance properties. The items are rated on a five-point Likert scale from "not at all" to "extremely". A cut-off of 11 on the anxiety scale has been proposed to reflect high anxiety.

On the day of surgery, the escort accompanied the patient into the reception area of the ORs. At the time of surgery, both were brought into the $\mathrm{OR}$, and the patient was connected to the monitoring equipment. The escort was encouraged to sit next to the patient and was allowed to give a hand, calm down the relative, or help with translation in cases where language was a barrier. After completing the WHO surgical safety checklist, the escort was led to the waiting area. In cases where the patient had hearing aids, visual aids or dentures, the escort would take those when leaving the OR. Following surgery, OR staff (nurse and anesthesiologist) completed questionnaires of their perception of the process (see below, secondary endpoints).

On postoperative day 1 , patients were asked whether the presence of their relative in the OR assisted in reducing their level of anxiety (did not help, not sure, or helped a lot). Additionally, the patient and escort were asked about their overall satisfaction of the process (see below, secondary endpoints).

\section{Measurements}

\section{Feasibility}

This is a feasibility study that assessed patient and escort reaction and possible complications during the course of escort presence in the OR. The primary endpoint was the success rate of the program. This comprised the proportion of relatives who completed the intervention without expressing their wish to leave the OR early or convey feeling dizziness or fainting.

\section{Patient, escort and medical staff perceptions}

Secondary end points included: (1) Satisfaction regarding the overall experience. This was assessed by asking the patients and escorts whether they would repeat this process should another operation be required. (2) Patient perception of the process in terms of anxiolysis. This was assessed by asking the patients whether or not relative presence had a significant anxiolytic effect. (3) Perception of the anesthesiologist and the nursing staff regarding: (i) whether escort presence helped improve communication and general well-being of the patient, (ii) whether this process should become standard care offered to elderly patients at their preoperative anesthesia visit, and whether they support this practice for the pediatric surgical patient. 


\section{Statistical analysis}

Most of the data collected is descriptive. The data was analyzed using SPSS Version 18.0. Quantitative variables were analyzed by mean and standard deviation (SD) and qualitative variables by frequency and percentages. The attitude of the different groups (patient, escort, medical and nursing staff) in this study to the process has been described using prevalence of answers collected from the various questionnaires. Fisher's exact t-test was used to compare qualitative variables between the groups. Pvalues less than 0.05 were considered to be significant.

\section{Results}

\section{Study population and main cause for participants wish to escort or be escorted to the OR}

Fifty patients and their escorts were recruited, and 44 sets of data were completed. One operation was cancelled due to patient's severe hypertension, in another case the surgeon opposed the process, and in 4 cases data was missing (for example due to postoperative delirium). Patients and escorts demographics are presented in table 1 . The majority of patients $(n=37,84 \%)$ had previous operation. All patients had visual or hearing impairment. A quarter confirmed that they have difficulty communicating in Hebrew. About one fifth described signs of confusion or forgetfulness, while none reported depression or anxiety disorder nor had received any medications for these disorders. Overall patients score for APAIS questionnaire was high $-18.3 \pm 6.3$. The escorts were mainly composed of the son or daughter of the patients.

The most prevalent answer for the patients' reasons for wishing to be escorted to the OR was to alleviate anxiety $(n=35,79.5 \%)$. Five patients indicated their need for help communicating, and 4 indicated they wished to alleviate their relative anxiety. Similarly, the main cause the escorts participated in this process was to decrease patients' anxiety $(n=33,75 \%)$ followed by their wish to assist with communications $(n=$ 11). Some commented that because of their own personal experience being surgical patients in the past, they felt that they can contribute to a more efficient process.

Primary endpoint Success rate of the program All escorting members completed the process, and none asked to leave the OR earlier than planned. None felt dizzy or fainted.

Secondary endpoints Satisfaction with the program The majority of participants were satisfied with the intervention; 41 (93\%) escorts and 33 (75\%) patients expressed their wish to repeat the process should their relative or themselves need another surgery. The three relatives who did not wish to repeat the process noted it was a stressful event. The eleven patients who replied negatively indicated that the process was of no value as they were neither anxious nor did they need any other help. Moreover, two were concerned that the process increased their relatives' anxiety. 
Patient perception of the process in terms of anxiolysis Twenty-seven patients (61.4\%) reported that the presence of the relative significantly helped reducing their anxiety.

Perception of the anesthesiologist and the nursing staff The nursing staff included mostly experienced OR nurses. Among anesthesiologist, there was a representation of both trainees and attendings (table 2). Although the majority of anesthesiologists [30 (68.2\%)] thought the patients' well-being was improved by escort presence, only 17 (38.6\%) would recommend this as routine practice. The nursing staff was less enthusiastic, with only $12(27 \%)$ admitting they felt there was a positive effect on patients' well-being and $8(18 \%)$ responding positively regarding making this practice routine. Interestingly, when questioned whether parents escorting a pediatric patient into ORs was a good practice, most of the nursing and medical staff [35 (79.5\%) and $30(68.2 \%)$; respectively] replied yes (figure 1).

\section{Discussion}

Patient- and family-centered care is an approach to the planning, delivery, and evaluation of healthcare that is grounded in a mutually beneficial partnerships among healthcare providers, patients, and families [19]. This approach is considered the standard of healthcare by many clinical practices. Studies, however, addressing family member presence in the $\mathrm{OR}$ are limited, with two notable exceptions; a policy in some hospitals of allowing parents to accompany their child into surgery and a policy of allowing the partner to be present in the labor ward during birthing or in the OR during cesarean delivery. Findings from several studies support the benefit of parental escort and suggest high levels of parental satisfaction $[7,20]$. Healthcare is faced with a dramatic growth in the number of elderly patients undergoing surgery to which it needs to adapt. Nevertheless, the well-being of the surgical elderly patient received little attention. The results from the present study suggest that the accompanying of the elderly into the OR by an escort is a feasible option that carries no evidenced complications when both patient and escort show interest in doing so.

In the present study, preoperatively assessed patients' anxiety levels were high and more than three quarters of the patients indicated alleviation of anxiety as the main reason for their wish to be escorted into the OR. Nevertheless, none of the patients had a history of depression or anxiety disorder nor had received any medications for these disorders. Similarly, in a prospective multi-center study in elderly undergoing cardiac surgery, patients with high levels of anxiety were unlikely to carry a clinical diagnosis of general anxiety disorder [11]. A quick evaluation of anxiety levels as part of the preoperative assessment may allow identification of high-risk patients for whom pharmacological or psychological interventions may be instituted. Although the intervention implemented in this study was applied to all participating patients (those with high and low anxiety levels), more than half of the study population noted a reduction in their levels of anxiety following this non-pharmacological intervention. Previous work showed that significant levels of patient-reported preoperative anxiety independently predicted a greater risk of in-hospital mortality or morbidity [11], thus alleviating anxiety might be clinically important. 
The patient and family centered care approach used in other populations (pediatrics, obstetrics) seems highly relevant in this particular population as well. This is especially apparent by the positive attitude of the patients and their escorts towards this study and the enthusiasm to participate in the escorting process should another occurrence appear. This was in marked contrast to the medical and nursing staff attitude, with the majority indicating that this process should not be offered routinely to elderly patients and their families. Objection of nursing staff to the study initiative is not new. A previous study [9] that examined the feasibility of family member presence in the OR during breast biopsy reported that approximately two third of the nurses do not believe that family members should have the option to be present during the procedure. Among their listed reservations were infection control, potential liability concerns, distractions to the circulating nurse, that family member might faint and several other "system barriers" as perceived by the nurses. In order to further develop the concept of family presence in the OR, the authors suggest, among other things, extensive education of the staff. Interestingly, in the present study when we asked about parents' presence during pediatric anesthesia, the majority of responders supported it. Numerous reports discuss the concept of "ageism" (age discrimination between elderly care and younger adults care) among healthcare providers [21]. While this is beyond the scope of this paper, the observation of differences in the attitude of the medical staff towards the surgical children versus elderly population, both of whom are in need of support, is alarming.

This study has several limitations. Firstly, this is a single center study and thus generalizability of the results to other geographic locations is limited. Additionally, there is a selection bias, as the participants are those who were initially interested in the escorting process. Lastly, the small sample size of this study has limited the ability to produce significant conclusions. However, it is worth noting that the aim of this study was to show the feasibility of the process with respect to complications that might arise during the course of escort presence in the OR.

\section{Conclusion}

The concept of family escort of the elderly into the OR is novel. The results from the study suggest that, in parallel to policies in other hospitalized patient populations, this intervention is feasible and may help alleviate patient's anxiety and increase patients and family satisfaction. Further studies in larger populations should evaluate the potential benefits of this practice to patients and their family members including short- and long-term effects on outcome. The medical staff objections towards making this a routine practice must be looked at further, with emphasis on the reasons for this objection, and how the concerns may be alleviated. Without the support of the immediate healthcare providers, this initiative would be impossible to institute.

\section{Declarations}

APAISAmsterdam Preoperative Anxiety and Information Scale OROperating Room 
STAIState Anxiety Scale

Ethical approval and consent to participate: Ethical approval for this study (Ethical Committee number 0212-14-TLV) was provided by the Ethical Committee of the Tel Aviv Sourasky Medical Center, Tel Aviv, Israel, and conforms to the Helsinki declaration. Informed consent was obtained from all subjects involved in this study.

Consent for publication: Not Applicable

Availability of data and materials: The summarized data from this study are included in the published article. The complete datasets used in this study are available from the corresponding author on reasonable request.

Competing interests: The authors declare that they have no competing interests.

Funding: There was no funding for this study.

Authors' contributions: LS and IM were responsible for the conception and design of the study. LS was responsible for data collection and analysis. IR was responsible for drafting the manuscript. All authors read and approved the final manuscript.

Acknowledgements: The authors wish to thank Anat Cattan, the research coordinator, for study management assistance.

\section{References}

1. Deiner S, Silverstein JH. Anesthesia for geriatric patients. Minerva Anestesiol. 2011;77:180-9.

2. Griffiths R, Beech F, Brown A, Dhesi J, Foo I, Goodall J, et al. Peri-operative care of the elderly 2014: Association of Anaesthetists of Great Britain and Ireland. Anaesthesia. 2014;69 Suppl 1:81-98.

3. Richards T. An age old problem. Bmj. 2007;335:698-698.

4. Francis R. Report of the mid staffordshire NHS foundation trust public inquiry. 2013.

5. Parliamentary and Health Ombudsman. Care and compassion? Report of the Health Service Ombudsman on ten investigations into NHS care of older people. Fourth Rep Heal Serv Comm Engl. 2011;29:104-6.

6. Makary MA, Segev DL, Pronovost PJ, Syin D, Bandeen-Roche K, Patel P, et al. Frailty as a predictor of surgical outcomes in older patients. J Am Coll Surg. 2010;210:901-8.

7. Messeri A, Caprilli S, Busoni P. Anaesthesia induction in children: a psychological evaluation of the efficiency of parents' presence. Paediatr Anaesth. 2004;14:551-6.

8. Institute for Patient- and Family-Centered Care. http://www.ipfcc.org.

9. Evans LA. Feasibility of family member presence in the OR during breast biopsy procedures. AORN J. 2008;88:568-86. 
10. Halm MA. Family presence during resuscitation: a critical review of the literature. Am J Crit Care. 2005;14:494-511.

11. Williams JB, Alexander KP, Morin J-F, Langlois Y, Noiseux N, Perrault LP, et al. Preoperative Anxiety as a Predictor of Mortality and Major Morbidity in Patients $>70$ Years of Age Undergoing Cardiac Surgery. The American journal of cardiology. 2013;111:137-42.

12. Chow A, Mayer EK, Darzi AW, Athanasiou T. Patient-reported outcome measures: the importance of patient satisfaction in surgery. Surgery. 2009;146:435-43.

13. Moerman N, van Dam FS, Muller MJ, Oosting H. The Amsterdam Preoperative Anxiety and Information Scale (APAIS). Anesth Analg. 1996;82:445-51.

14. Miller KM, Wysocki T, Cassady JFJ, Cancel D, Izenberg N. Validation of measures of parents' preoperative anxiety and anesthesia knowledge. Anesth Analg. 1999;88:251-7.

15. Waterman H, Mayer S, Lavin MJ, Spencer AF, Waterman C. An evaluation of the administration of sub-Tenon local anaesthesia by a nurse practitioner. $\mathrm{Br} J$ Ophthalmol. 2002;86:524-6.

16. Cassady JFJ, Wysocki TT, Miller KM, Cancel DD, Izenberg N. Use of a preanesthetic video for facilitation of parental education and anxiolysis before pediatric ambulatory surgery. Anesth Analg. 1999;88:246-50.

17. Spencer C, Franck LS. Giving parents written information about children's anesthesia: are setting and timing important? Paediatr Anaesth. 2005;15:547-53.

18. Maurice-Szamburski A, Loundou A, Auquier P, Girard N, Bruder N. Effect of patient-controlled sedation with propofol on patient satisfaction: a randomized study. Ann Fr Anesth Reanim. 2013;32:e171-5.

19. Millenson ML, Shapiro E, Greenhouse PK, DiGioia AMIII. Patient- and Family-Centered Care: A Systematic Approach to Better Ethics and Care. AMA J ethics. 2016;18:49-55.

20. Odegard KC, Modest SA, Laussen PC. A survey of parental satisfaction during parent present induction of anaesthesia for children undergoing cardiovascular surgery. Paediatr Anaesth. 2002;12:261-6.

21. White SM. Ethical and legal aspects of anaesthesia for the elderly. Anaesthesia. 2014;69 Suppl 1:45-53.

\section{Tables}

\section{Table 1 - patient and escort demographics}




\begin{tabular}{|c|c|c|}
\hline & $\begin{array}{l}\text { Patient } \\
\mathrm{n}=44\end{array}$ & $\begin{array}{l}\text { Escort } \\
n=44\end{array}$ \\
\hline Age, years $[$ mean $(\mathrm{SD})]$ & $77.9(5.5)$ & $53.6(13.1)$ \\
\hline Gender: & & \\
\hline Female, n (\%) & $24(54.5)$ & $26(59.0)$ \\
\hline Male, n (\%) & $20(45.5)$ & $18(41.0)$ \\
\hline Hearing impairment, n (\%) & $21(47.7)$ & NR \\
\hline Visual impairment, n (\%) & $33(75.0)$ & NR \\
\hline Use of dentures, $\mathrm{n}(\%)$ & $29(66.0)$ & NR \\
\hline Self-reported signs of confusion or forgetfulness, $\mathrm{n}(\%)$ & $10(22.7)$ & NR \\
\hline Not fluent in Hebrew, n (\%) & $11(25.0)$ & 0 \\
\hline $\begin{array}{l}\text { Affiliation with patient: Son/daughter, n (\%) } \\
\text { Partner, n (\%) } \\
\text { Others, n (\%) }\end{array}$ & NR & $\begin{array}{l}27(61.4) \\
12(27.3) \\
5(11.3)\end{array}$ \\
\hline
\end{tabular}

NR, not relevant

Table 2 - Physicians and nurses' demographics

\begin{tabular}{|c|l|l|}
\hline & $\begin{array}{l}\text { Physicians } \\
\mathrm{n=44}(\%)\end{array}$ & $\begin{array}{l}\text { Nurses } \\
\mathrm{n}=\mathbf{4 4}(\%)\end{array}$ \\
\hline $\begin{array}{c}\text { Gender: } \\
\text { Female }\end{array}$ & $\begin{array}{l}11(25.0) \\
33(75.0)\end{array}$ & $\begin{array}{l}24(54.5) \\
20(45.5)\end{array}$ \\
\hline Male & $26(59.0)$ & $10(22.7)$ \\
\hline $\begin{array}{l}\text { Seniority status: } \\
\text { Trainee in anesthesia / Nurse for < } 10 \text { years } \\
\text { Attending anesthesiologist / Nurse > 10 years }\end{array}$ & $18(41.0)$ & $34(77.3)$ \\
\hline
\end{tabular}


Figures

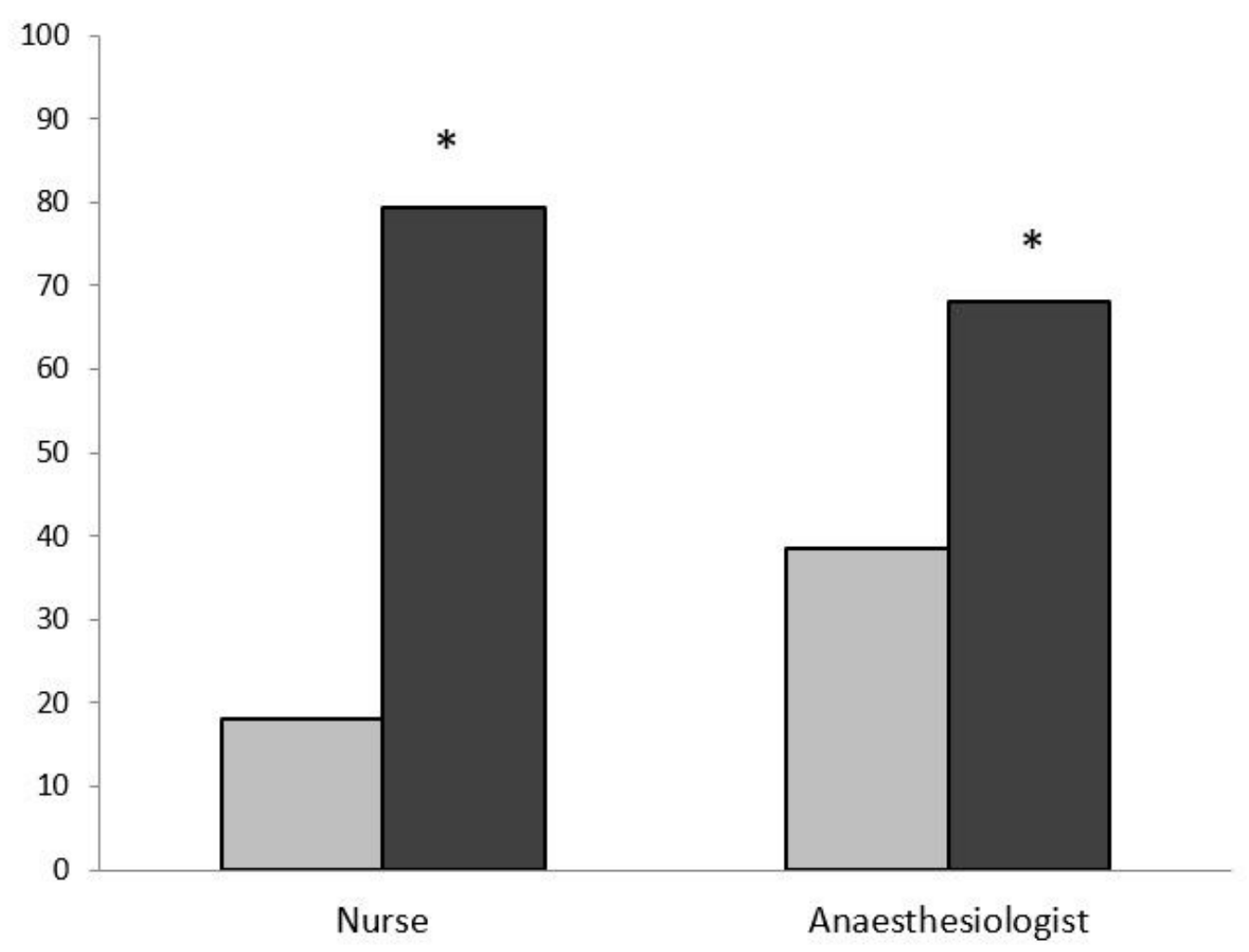

Percentage of nurses and anesthesiologists supporting the practice of the elderly patient and relative ( $\square$ ) or parents of the child ( $\square$ ) escort into the operating room; * $p<0.05$ vs the other group

Figure 1

Staff support for the practice of escorting patients 